\title{
O DESVELAR DAS COMPETÊNCIAS DOS INTRAEMPREENDEDORES: UM ESTUDO EXPLORATÓRIO EM EMPRESAS DE SERVIÇOS
}

\section{Disclosure of Intrapreneurs' Competencies: An Exploratory Study into Public Utility Providers}

\author{
Carlos Eduardo Munhoz \\ Faccamp - Faculdades de Campo Limpo Paulista \\ cemunhoz@hotmail.com \\ Vania Maria Jorge Nassif \\ Faccamp e Universidade Mackenzie \\ vania.nassif@uol.com.br
}

Submissão: $18 / 05 / 2011$

Aprovação: 20/04/2012

\section{Resumo}

Este artigo se propõe a identificar e analisar quais são as competências que caracterizam os intraempreendedores, sob a ótica deles mesmos e dos empreendedores de duas empresas prestadoras de serviços do segmento de água, energia elétrica e gás. Trata-se de uma pesquisa de natureza exploratória e interpretativista, cujo método é o qualitativo. Participaram da pesquisa oito pessoas sendo dois empreendedores e seis intraempreendedores. A entrevista com roteiro semiestruturado foi o instrumento eleito para levantamento de dados e os resultados foram tratados por meio da análise de conteúdo. As conclusões indicam que pela natureza da atividade desenvolvida pelos intraempreendedores, as demandas encaminham para ações já delineadas, visando o cumprimento das exigências contratuais. Esses aspectos evidenciam que as competências mais relevantes para os intraempreendedores foram conceituais, de inovação, organizador-administrativas e de comprometimento, entre outras. Observou-se que as ações intraempreendedoras muitas vezes acontecem de forma despercebida em função da dinâmica da empresa e que a forma de gestão é um condicionante da liderança empreendedora, que delega e abre caminhos para uma responsabilidade dos colaboradores.

Palavras-chave: empreendedorismo, intraempreendedorismo, competências, serviços 


\begin{abstract}
This research aims to identify and analyze which competencies characterize the intrapreneurs, in their own perspective as well as that of the entrepreneurs of two companies that provide services in the water, electricity and gas sectors. The research is exploratory and interpretive in nature and the method is qualitative. Eight people have taken part in this research, two of which are entrepreneurs and six are intrapreneurs. The interview with a semi-structured road map was the instrument chosen for the data collection and the results were analyzed by means of content analysis. The conclusions indicate that, by the nature of the activity developed by the intrapreneurs, the demands point towards actions already outlined aimed at the fulfillment of the contractual obligations. These aspects demonstrate that the most relevant competencies for the intrapreneurs were conceptual, innovational, organizational/administrative and committal, among others. It has also been observed that many times intrapreneurial actions aren't perceived as a result of the dynamics of the company and that the management style is a requirement of the entrepreneurial leadership that delegates and paves the way for the responsibility of the collaborators.
\end{abstract}

Keywords: entrepreneurship, intrapreneurship, competencies, services 


\section{Introdução}

A prestação de serviços no mercado corporativo está associada à contratação de uma empresa que deverá proporcionar à outra parte a entrega de um resultado intelectual. Esse resultado pode ser de cunho manual, físico e muitas vezes se caracteriza pela intangibilidade, inseparabilidade, ou seja, é produzido e utilizado ao mesmo tempo e pode não resultar na posse de um bem a outra parte.

A atividade de uma prestadora de serviços muitas vezes visa o preenchimento de uma lacuna ou conhecimento não dominado por parte da contratante ou o desenvolvimento de tarefas que não são da sua natureza empresarial.

Diversos são os motivos que podem levar uma empresa a contratar uma prestadora de serviços, mas independente de quais sejam, haverá uma interação entre estas empresas na condução dos trabalhos e no resultado final.

Quando se analisa a prestação de serviços realizada pelas empresas observa-se que além dos aspectos comuns da natureza dos seus trabalhos, estas necessitam de profissionais qualificados e de um quadro de colaboradores capaz de promover interações e inovações constantes, comprometidos e que demonstrem um perfil que o diferencie de outros profissionais. Para Baron e Shane (2007), um corpo profissional adequado precisa primar pela eficácia dos trabalhos em equipe e pelo estabelecimento de papéis claramente definidos.

As empresas Tecdata Engenharia e Serviços Ltda. e Allsan Engenharia e Administração Ltda., foram selecionadas para participar desta pesquisa pelas similaridades que estas empresas apresentam no seu portfólio de negócios e porte. Ambas prestam serviços para Concessionárias de Serviços Públicos de Água e Esgoto e tem seus contratos de prestação de serviços gerenciados de formal autônoma um dos outros o que classificam como Unidade de Negócio. As gestões contratuais das duas empresas contemplam profissionais que são oficialmente designados como prepostos junto aos clientes podendo tomar todas as decisões necessárias para execução dos serviços, além de responderem oficialmente por todas as ações de prestação de serviços que são executadas durante a vigência contratual.

Foram entrevistados os sócios cotistas das duas empresas e seis intraempreendedores por eles indicados, sendo três da cada organização, por apresentarem características intraempreendedoras à luz dos sócios cotistas. 
Assim, é de grande relevância entender o papel destes colaboradores que atuam como intraempreendedores no contexto das empresas, como as relações entre eles e seus gestores e quais são as diferenças dos papeis de empreendedor e intraempreendedor no contexto das empresas prestadoras de serviços.

Para Garcia et al. (2008) o intraempreendedorismo é fruto de comportamentos de indivíduos dentro de organizações associados à sua capacidade de criatividade e inovação, guiados por um sentido de visão e integração, determinação e competitividade, por meio de um processo de liderança e iniciativa e voltados para resultados e busca de oportunidades. Estes pressupostos encontram similaridade na visão de $\mathrm{Li}$ (2007), que define intraempreendedorismo como uma forma de reorganizar os recursos existentes das empresas a fim de desenvolver produtos, mudanças organizacionais, tendo como objetivo a criação de uma vantagem competitiva para organização.

Embora sejam temas recorrentes na literatura, vários são os estudos que apontam para a necessidade de se aprofundar esse conhecimento, cujo intuito é o de contribuir com a ampliação do tema proposto.

Após analisar a literatura disponível sobre os conceitos de competências empreendedora, optou-se pelos os estudos de Man e Lau (2005), Prahald e Hamel (2005), Le Bortef (2003), Fleury e Fleury (2001), Dutra (2004), Zarifian (2003) e Mello et al. (2006), com diferentes faces e aplicações a fim de identificar quais são as competências que caracterizam os intraempreendedores das empresas prestadoras de serviços.

Para verificar quais são as competências que caracterizam estes intraempreendedores sob sua ótica e dos seus empreendedores, foram cumpridas etapas de pesquisa que estão aqui apresentadas em quatro seções. A primeira delas faz uma revisão da literatura sobre empreendedorismo e intraempreendedorismo. A segunda parte descreve as competências empreendedoras, seguida pela terceira parte que apresentada os procedimentos metodológicos utilizados. Por último, na quarta seção, busca-se apresentar os resultados e análise dos dados para responder à questão de pesquisa formulada e refletir sobre os resultados.

O objetivo geral deste artigo foi o identificar quais são as competências que caracterizam estes intraempreendedores, e esse objetivo foi desmembrado nos objetivos específicos que procurou conhecer as ações intraempreendedoras, os fatores inibidores e facilitadores, bem como as atuações e desafios para o desenvolvimento dos intraempreendedores e as políticas e práticas que contribuem para o desenvolvimento do intraempreendedorismo 


\section{Empreendedorismo e Intraempreendedorismo}

Falar de empreendedor e de empreendedorismo não é tarefa fácil, tendo em vista que se trata de um conceito multifacetado, complexo e de difícil compreensão (Falcone e Osborne, 2005).

Simon (2002) diz que o empreendedorismo é o processo de identificar, desenvolver e trazer uma visão para a vida, impulsionando ideiais inovadoras, oportunidades e novas formas de fazer um novo empreendimento, sempre pensando nas condições de riscos e incertezas.

Filion (1999) observa que são varias as áreas da ciência que se dedicam em entender este fenômeno dentre outras como a economia, a psicologia, a história e a sociologia.

$\mathrm{Na}$ ciência econômica a figura do empreendedor é estudada há muito tempo. Um dos primeiros estudiosos foi Cantillon (1755), considerado por muitos como criador do termo empreendedor. Say (1832), Schumpeter (1934) e Shapero (1980), contribuíram para que os economistas tivessem um constructo do que seja o empreendedor.

Hisrich et al. (2009), sintetiza esta visão econômica quando conceitua um empreendedor como aquele que combina recursos, trabalho, materiais e outros ativados para tornar seu valor maior do que antes, introduzindo mudanças, inovações e uma nova ordem.

Outra vertente de estudiosos são os comportamentalistas como McClelland (1987) que abriu caminho para a abordagem comportamental nas pesquisas em Empreendedorismo, dando uma contribuição significativa ao estudar indivíduos com comportamentos que, segundo o autor, poderiam ser imitados.

A pesquisa de McClelland estava limitada a alguns setores econômicos, não tendo o indivíduo empreendedor como objeto direto ou especifico do seu estudo. Mas foi possível identificar traços comportamentais comuns entre estes indivíduos como à necessidade de sucesso, de reconhecimento, de poder e controle, haja vista a necessidade de realização ser a principal força motivadora do comportamento empreendedor.

Esses traços comportamentais mostram que os empreendedores têm maior propensão na identificação de novas oportunidades de negócios e em assumir riscos calculados, seja ao iniciar um novo negócio ou nas tomadas de decisões do empreendimento já existente. McClelland (1987) afirma ainda que empreendedores tendem a estabelecer metas pessoais desafiadoras, porém realistas e gostam de situações que seja possível chamarem para si a responsabilidade nas soluções de problemas. 
Filion (1999) afirma que depois de McClelland, houve um domínio dos comportamentalistas no campo de estudo sobre empreendedorismo por 20 anos. Eles tinham como objetivo definir o que são empreendedores e suas características, uma vez que as ciências do comportamento haviam encontrado um consenso sobre as metodologias mais válidas e confiáveis em relação a outras disciplinas.

Para Teorodo e Oliveira (2006) o empreendedor procura criar situação em que possa obter um retorno de suas ações e comportamentos e, desta forma, utilizar estas opiniões para seu aprimoramento.

A busca no entendimento do fenômeno empreendedorismo e de seu principal ator o empreendedor apresentado por varias áreas de estudos podem ser também compreendidas através da proposta de Cunninghan e Lischeron (1991) que identificaram seis linhas de pensamentos ou escolas do empreendedorismo.

A primeira seria a Escola Bibliográfica focada na história de vida de grandes empreendedores. A segunda Escola Psicológica tem como principal característica estudar a inovação provocada pelo empreendedorismo. Na Escola de Administração os estudos sugerem que o empreendedor é uma pessoa que organiza e administra um negócio, assume riscos de prejuízo e os lucros inerentes a ele, planejando, supervisionando, controlando e direcionando o empreendimento. Já a Escola da Liderança mostra que o empreendedor é um líder que mobiliza as pessoas em torno de objetivos e propósitos. A Escola Corporativa diz que as habilidades empreendedoras podem ser úteis em organizações complexas. E por último a Escola dos Intraempreendedores que analisa o processo e atuação dos empreendedores chamados de corporativo.

Timmons (1994) apresentou três fatores que considera essencial para o empreendedorismo. O primeiro fator apontado foi o da oportunidade, sendo esta decisiva na tomada de decisão da permanência ou não no empreendimento. O segundo fator se refere à equipe que compõe o empreendimento, ou seja, a equipe empreendedora, através da análise do perfil de cada um dos membros. Já o terceiro fator são os recursos necessários para iniciar o empreendimento.

A Escola dos Intraempreendedores identificada por Cunnighan e Lischeron (1991) e o fator Equipe que compõe o empreendimento de Timmons (1994), mostram que os estudos sobre empreendedorismo lançam uma luz não somente sobre o empreendedor, mas também sobre os colaboradores internos das organizações como atores que fazem parte do entendimento deste fenômeno. 
Neste sentido Baron e Shane (2007) afirmam que os recursos humanos são essenciais em qualquer empreendimento. A escolha de futuros sócios deve ser pautada pela expertise, conhecimentos e competências que virão agregar ao empreendimento. Importante como a escolha correta de eventuais sócios é da equipe de colaboradores que farão parte do funcional do empreendimento. Um corpo profissional adequado precisa primar pela eficácia dos trabalhos em equipes e pelo estabelecimento de papéis claramente definidos.

Sob esse prisma, Bessant e Tidd (2009), confirmam que o processo criativo inicial depende da habilidade e inspiração de um indivíduo específico, ou seja, o empreendedor, mas o processo final exige contribuição de inúmeras pessoas no decorrer de um determinado período de tempo.

Do exposto fica claro que a maioria das definições de empreendedor $\mathrm{e}$ empreendedorismo se refere aos comportamentos inovadores e criativos, além da percebida capacidade de organização e captação de recursos para transformar oportunidades em negócios.

Portanto, a definição de Hisrich et al. (2009) de que empreendedores são indivíduos que possuem suas próprias empresas, assumindo os riscos do empreendimento e dispondo para isso de seus próprios recursos. Passa a ser o conceito utilizado neste artigo para diferenciar o empreendedor dos outros indivíduos que fazem parte da sua equipe e que podem apresentar características conceituadas como intraempreendedoras.

Antes de discutir sobre as competências empreendedoras que caracterizam quem são os intraempreendedores é necessário conhecer quem são estes atores sociais.

Há diferentes visões acerca de intraempreendedores. Oliveira et al (2008) corrobora com esse pensamento dizendo que embora o conceito de intraempreendedorismo exista há mais de vinte anos, não há uma unanimidade entre os autores na definição deste conceito, uma vez que são encontrados vários termos na literatura que classificam este fenômeno nas organizações. Estes autores estudaram as linhas de pesquisa sobre intraempreendedorismo e organizações empreendedoras por meio da revisão da documentação de 1996 a 2006, e para eles intraempreendedorismo e empreendedorismo corporativo são conceitos similares. A diferença estaria na interpretação de como estes são aplicados.

Para Hashimoto (2009) foram Covin e Miles (1999) que melhor demonstraram as diferenças entre empreendedorismo corporativo e intraempreendedorismo, aos estabelecerem três divisões de classificação do empreendedorismo corporativo. 
A primeira se refere a uma organização já existente que promove o lançamento de novos negócios alinhado com a concepção de empreendedorismo corporativo, tendo suas decisões estratégicas concentradas no nível organizacional. Esta concepção vem ao encontro com a definição de Antoncic e Hisrich (2001) para quem empreendedorismo corporativo é o empreendedorismo dentro da empresa já existente, tratando-se de um processo de identificação e desenvolvimento de oportunidades independentemente dos recursos disponíveis.

A segunda divisão é tocante ao indivíduo que tem novas idéias para produtos e serviços no ambiente organizacional sendo caracterizado como intraempreendedor, dentro do que é chamado de empreendedorismo corporativo autônomo ou informal. Esse tipo de empreendedorismo ocorre pela ação do colaborador mesmo quando a organização não oferece um clima favorável ou apropriado à geração de novos produtos, serviços, processos, ou seja, o empregado é capaz de gerar um processo de inovações corporativas. E a terceira classificação ocorre quando uma organização tem uma filosofia empreendedora, isto é, existe um empreendedorismo corporativo formal ou induzido. No empreendedorismo corporativo formal a organização busca facilitar de todas as formas o surgimento de oportunidades empreendedoras e suas iniciativas entre seus colaboradores que também podem ser chamados de intraempreendedores. Stevenson et al. (1999) corroboram com o conceito quando pontuam que o empreendedorismo organizacional ou corporativo formal é o processo pelo qual indivíduos numa organização perseguem as oportunidades sem serem donos dos recursos que controlam correntemente. Outros autores têm uma abordagem mais ampla, usando o termo intraempreendedor para descrever indivíduos que tenham capacidade de analisar o ambiente e tomar medidas que possam tirar proveito das situações apresentadas. Esse pensamento é respaldado por Pinchot e Pellmam (2004) para quem o intraempreendedor é aquele que transforma uma idéia em realidade dentro de uma empresa, podendo ser ou não a pessoa a apresentar primeiro esta idéia, mas que arregaça as mangas e faz o que é preciso ser feito para alcançar os melhores resultados para as atividades empresariais.

Neste sentido estudo desenvolvido por Garcia et al. (2008) tentou identificar as ações do comportamento intraempreendedor através de uma escala de mensuração. Esta pesquisa indica que o intraempreendedorismo é fruto de comportamentos de indivíduos dentro de organizações associados à sua capacidade de criatividade e inovação, guiados por um sentido de visão e integração, determinação e competitividade, por meio de um processo de liderança e iniciativa e voltados para resultados e busca de oportunidades. 
A pesquisa de Garcia et al.(2008) encontram similaridade na visão de Ling (2007), que define intraempreendedorismo como uma forma de reorganizar os recursos existentes das empresas a fim de desenvolver produtos, mudanças organizacionais, geração de novos negócios e novos desafios, tendo como objetivo a criação uma vantagem competitiva para organização

Para Pin et al. (2010), o intraempreendedorismo é uma forma eficaz de promover o crescimento sustentável das empresas. Esses autores fizeram uma revisão do intraempreendedorismo sob a perspectiva da gestão de recursos humanos na China e apontam que as competências intraempreendedoras têm impacto direto no empreendimento e ressaltam a importância no desenvolvimento destas competências como forma de reforçar o desempenho das organizações.

Com base no exposto, conhecer e identificar as competências que caracterizam os intraempreendedores pode contribuir para o desenvolvimento e melhoria das atividades empresariais, inclusive das empresas prestadoras de serviços, como forma de ajudar na compreensão do que será exigido dos colaboradores para um bom desempenho profissional, possibilitando as empresas e aos colaboradores executarem ações conjuntas para desenvolver estas competências. 


\section{Competências Empreendedoras}

A definição do que é competência e estudos sobre o tema são facilmente encontradas na literatura nacional através de diversos pesquisadores, entretanto, pesquisas focando competências empreendedoras ainda são incipientes.

O conceito de competências individuais segundo Mello et al. (2006) podem ser concebidas como características que englobam diferentes traços de personalidade, habilidades e conhecimentos, influenciados pela experiência, capacitação, educação, história familiar e aspectos demográficos. Diante do conceito de Mello et al. (2006) sobre competências individuais lançou-se um olhar sobre como as competências são conceituadas no ambiente organizacional. Zarifian (2003) fundamenta seu conceito de competência em três elementos: competência na tomada de iniciativa e responsabilidade frente a situações enfrentadas pelo profissional; competência apoiada por um conhecimento adquirido de inteligência prática; e competência como a capacidade de mobilizar pessoas a respeito de uma situação, assumindo responsabilidades e dividindo desafios.

Pode-se acrescentar que o conceito de competência permite estabelecer o que é esperado da pessoa de forma alinhada ao intento estratégico e às competências organizacionais. $\mathrm{O}$ conceito de complexidade permite melhor especificar e mensurar a entrega da pessoa para uma organização (Dutra, 2004).

Fleury e Fleury (2001) sintetizaram os conceitos apresentados de competências até aqui quando definem competência como um saber agir responsável e reconhecido, que implica mobilizar, integrar, transferir conhecimentos, recursos e habilidades, que agreguem valor econômico à organização e social ao indivíduo. Le Boterf (2003) amplia o conceito das competências para o âmbito organizacional quando define que a competência de uma empresa ou de uma de suas unidades não equivale à soma das competências de seus membros. $\mathrm{O}$ valor do capital (de competência) depende não tanto de seus elementos constitutivos, mas da capacidade da combinação ou da articulação entre esses elementos. Assim, competência coletiva emerge da cooperação e sinergia existentes entre as competências individuais.

O conceito de Le Boterf (2003) encontra apoio na definição de competência apresentado por Prahalad e Hamel (2005), que definem competência como uma articulação de recursos organizacionais, um aprendizado da organização, um saber-fazer coletivo e complexo e à integração de múltiplas correntes tecnológicas no que diz respeito à coordenação de diversas habilidades. 
Conforme visto as competências individuais quando empregadas no contexto organizacional são fontes de inovação, transferência de conhecimento, mobilização de pessoas, aprendizado organizacional, além de agregarem valor econômico e social para uma empresa entre outros benefícios. Pesquisa e prática relacionadas com competência são tipicamente impulsionadas pelas aspirações de alcançar um desempenho superior e potencial que traga um ganho econômico ou o sucesso de um empreendimento.

Mas, além dessas concepções estudadas no escopo de competências, Mitchelmore e Rowley (2008) fizeram um trabalho sobre revisão da literatura sobre competências e competências empreendedoras. Para estes autores as competências têm muitas faces e aplicativos gerando diferentes modelos, quer seja no plano individual, grupal ou mesmo organizacional. Por outro lado, esses autores pontuam que as competências empreendedoras se baseiam em diferentes abordagens e conceitos, que ao revisitarem a literatura perceberam que as competências empreendedoras propiciam uma visão mais integrada, independente do ambiente de trabalho, setores e ramos de atuação. Esses autores apontam Man e Lau (2000), como sintetizadores dos estudos de competências empreendedoras, ao considerarem que eles foram os pioneiros em destacar competências empreendedoras diferentemente do que os autores vinham trabalhando competências.

Para Man e Lau (2000), as competências são um elo das características pessoais com as profissionais e estão relacionados com a capacidade do empreendedor em desempenhar seu papel e nesse estudo, esses autores contemplaram um conjunto de seis competências empreendedoras, procurando explicar como empreendedores atuam empreendedoristicamente. Continuando a pesquisa, Man e Lau em 2005, ampliam para dez áreas de competências, quais sejam: 1) Competências de Oportunidade; 2) Competências de Relacionamento; 3) Competências Conceituais; 4) Competências de Inovação; 5) Competências Organizadoras / Administrativas; 6) Competências Sociais; 7) Competências Estratégicas; 8) Competências de Comprometimento; 9) Competências de Aprendizagem; e 10) Competências de Equilíbrio Trabalho/Vida Pessoal. Esse conjunto, de certa forma, contribuiu para melhor compreender o escopo da presente pesquisa.

Não obstante, o comportamento empreendedor e intraempreendedor, assim como as atividades desses atores sociais serem complexas, são de grande relevância entender os desafios por eles enfrentados e, consequentemente, em quais competências se apóiam frente às atividades por eles vivenciadas. A presente pesquisa, por meio dos procedimentos metodológicos demonstra como a pesquisa foi realizada procurando dar evidências e 
subsídios para melhor entender as ações, políticas e práticas que podem contribuir ou inibir para o desenvolvimento do intraempreendedorismo. 


\section{Procedimentos Metodológicos}

Está pesquisa foi de natureza exploratória que segundo Godoy (1995), envolve levantamento bibliográfico, entrevistas com pessoas que tiveram ou tem experiências práticas com o problema pesquisado e análise de exemplos que estimulem a compreensão. Possui ainda a finalidade básica de desenvolver, esclarecer e modificar conceitos e idéias para a formulação de abordagens posteriores. Nesse sentido adota uma posição epistemológica interpretativa, procurando explicar o fenômeno em estudo, segundo o ponto de vista dos sujeitos pesquisados, não lhes impondo pontos de vista externos e formulados aprioristicamente. O método utilizado foi o qualitativo, por ser considerado o mais apropriado ao se considerar o problema da presente pesquisa. O instrumento eleito para coletar dados foi entrevista em profundidade apoiados em dois roteiros semiestruturados, um específico para o empreendedor e outro para os intraempreendedores.

As entrevistas foram realizadas nas empresas Tecdata e Allsan e contou com a participação de um sócio cotista de cada empresa e com seis intraempreendedores por ele indicados. Vale ressaltar que as empresas autorizaram a exposição de seus nomes, mantendo preservado o nome dos respondentes da pesquisa. Os grupos atendem a dois perfis: 1) Sócio cotista e executivo da organização empreendedora, com vivência profissional na área de prestação de serviços e conhecimento do seu quadro de colaboradores, tendo em vista que o mesmo indicou os profissionais que ele classificou como intraempreendedor da sua organização para fazerem parte desta pesquisa; e 2) Colaboradores indicados como intraempreendedores pelos sócios cotistas e executivos da organização empreendedora para participar da pesquisa.

Todas as entrevistas foram realizadas presencialmente, transcorrendo num clima favorável, em ambiente isolado, estando presente o pesquisador e o entrevistado. Os respondentes demonstraram interesse pelo objeto desta pesquisa.

Para facilitar a identificação dos participantes da pesquisa, doravante os mesmos serão intitulados, da empresa Tecdata, como T0 para o sócio cotista e T1, T2 e T3 os três intraempreendedores por ele indicado. O sócio cotista da empresa Allsan será chamado de A0 e os três intraempreendedores por ele indicados de A1, A2 e A3. As indicações dos intraempreendedores por empresa surgiram de forma espontânea, e em nenhum momento foi estipulado ou mesmo delimitado o número de intraempreendedores apontados por seus executivos para participar da pesquisa, mas coincidentemente, cada sócio cotista indicou três 
colaboradores que julgaram ter o perfil intraempreendedor. Assim, a pesquisa contou com oito respondentes. Todas as entrevistas foram gravadas e transcritas na integra de forma fiel as falas e expressões utilizadas, de forma a assegurar o registro das informações passadas, no nível de detalhe e fidedignidade esperada, sendo que todas estão transcritas e foi objeto do tratamento dos dados.

Os dados desta pesquisa foram tratados por meio da técnica denominada "análise de conteúdo" proposta por Bardin (1977). Essa técnica consiste em analisar discursos diversos e todo tipo de comunicação. Ela parte do pressuposto que, por trás do discurso aparente, simbólico e polissêmico, esconde-se um sentido a ser desvendado.

Com base nesses dados e na caracterização das respostas foram estabelecidas seis categorias assim definidas: 1) Conceito de Empreendedor; 2) Conceito de Intraempreendedor; 3) Competências intraempreendedoras; 4) Ações intraempreendedoras; 5) Fatores inibidores e facilitadores para desenvolvimento do intraempreendedorismo; 6) Atuação e desafio para o desenvolvimento do intraempreendedorismo e 7) Políticas e práticas para o desenvolvimento do intraempreendedorismo.

Com as categorias criadas entende-se ter contemplado um conjunto de elementos passíveis de serem observados, respaldado na literatura apresentada, com base nas perguntas da pesquisa em uma forma lógica de análise. Os resultados foram analisados qualitativamente, procurando compreender a opinião dos entrevistados, de uma forma mais direcionada, sobre os comportamentos caracterizados como intraempreendedor de acordo com o referencial teórico aqui proposto.

Para a identificação das competências que caracterizam os intraempreendedores, esta pesquisa tomou como base os relatos, além de eventualmente buscar dados de exemplos reais da atuação no cotidiano profissional.

Todos os dados desta pesquisa foram organizados e armazenados em arquivos de voz e as transcrições em arquivos eletrônicos. Para Godoy (2005), um relatório de pesquisa revela uma das possíveis interpretações para o fenômeno em estudo, a qual não é única nem a mais correta, é possível aceitar a ideia de que outros pesquisadores possam desenvolver outras representações do evento estudado além de possibilitar auditorias e avaliações futuras. 


\section{Resultados E Análise Dos Dados}

As empresas prestadoras de serviços precisam ser ágeis e capazes de atenderem as necessidades e desejos dos seus clientes. É crescente o reconhecimento da figura do intraempreendedor dentro das organizações e o reconhecimento de que suas ações e comportamentos podem gerar uma vantagem competitiva em relação aos demais concorrentes do mercado. Identificar e entender quais são as competências que caracterizam este intraempreendedores, as ações que podem inibir ou facilitar o intraempreendedorismo passou a ser pauta de discussão de muitas empresas.

Os resultados e análise dos dados discutidos neste item consideram os diferentes pontos de vista dos empreendedores e intraempreendedores entrevistados, além de apresentar as categorias de respostas. Estes resultados também buscaram explorar o conceito de empreendedor e intraempreendedor no sentido de contribuir para melhor entendimento destes atores sociais no contexto em que estão inseridos.

O conceito de empreendedor foi explorado junto aos dois sócios cotistas das empresas Tecdata e Allsan. Os empreendedores T0 e A0 demonstraram familiaridade com tal conceito e consideram que o empreendedor identifica oportunidades de negócios, corre riscos, busca inovações, sempre atuando de forma pró-ativa.

Para T0 o empreendedor tem que realizar novos empreendimentos, gerar inovação e capacidade de assumir riscos. Já A0 salienta que o empreendedor tem que correr vários riscos.

Observa-se que estes pressupostos são concordantes com McClelland (1987) e Nassif et al. (2009) que pontuam acerca do conceito e das ações de um empreendedor. Estes autores confirmam que o empreendedor tem suas ações pautadas pela iniciativa, realização, autonomia, aposta no trabalho, diferenciação e transformação de idéias em oportunidades.

O conceito de intraempreendedor foi explorado junto ao grupo participante da pesquisa, empreendedores e intraempreendedores. Os dois empreendedores consideram o termo familiar, que, para eles:

Intraempreendedor é aquele colaborador que de certa forma assume o papel do dono na atividade que é delegada, ou seja, ele toma decisões, assume riscos, responde por eles, ele faz o papel do dono. [TO]

Intraempreendedor tem características semelhantes do empreendedor, vai além das atribuições designadas pela empresa, busca novas oportunidades, trabalha como se a empresa fosse dele e esta sempre presente nas atividades empresariais. [A0] 
Estes pressupostos são respaldados por Pinchot e Pellman (2004) para quem o intraempreendedor é aquele que transforma uma idéia em realidade dentro de uma empresa, podendo ser ou não a pessoa que apresentou primeiro esta idéia, mas que arregaça as mangas e faz o que é preciso ser feito para alcançar os melhores resultados para as atividades empresariais.

A convergência destes conceitos com os pensamentos dos intraempreendedores entrevistados pode ser observada nas ilustrações abaixo:

Eu cuido mais do que é dos outros do que o que é meu. [T1]

Dá uma idéia de que seja a pessoa que tem o espírito empreendedor, mas um cara muito guardado, muito reservado, muito intrínseco, muito pé no chão, no sentido de não querer fazer vôos que ele não conheça, diferente do empreendedor. [T2]

O intraempreendedor é a pessoa que dentro da empresa age como se fosse o dono, buscando resultado, a satisfação da empresa, a harmonia da equipe. [T3]

Pessoalmente posso falar que eu sou um intraempreendedor. O intraempreendedor veste a camisa da empresa e tenta trazer um resultado melhor para a empresa e que no futuro indiretamente trará um resultado diretamente para ele. [A1]

A gente trata assuntos de novos negócios, de novas perspectivas para a empresa, parece que falamos a mesmo língua, ou seja, estamos sempre na mesma sintonia. [A2]

Acredito que tenha uma confiança pelo meu histórico, tem uma aposta em mim pelo meu passado e presente. [A3]

Foi possível identificar o perfil de intraempreendedor entre os respondentes, conforme observado por Garcia et al. (2008), Ping et al. (2010) e Li (2007), que pontua que o intraempreendedor é capaz de reorganizar os recursos existentes das empresas a fim de desenvolver produtos, mudanças organizacionais, geração de novos negócios e novos desafios, tendo como objetivo a criação de uma vantagem competitiva para a organização.

A Figura 01 representa as seis categorias analisadas, com exceção dos conceitos de intraempreendedor e empreendedor já apresentados: 


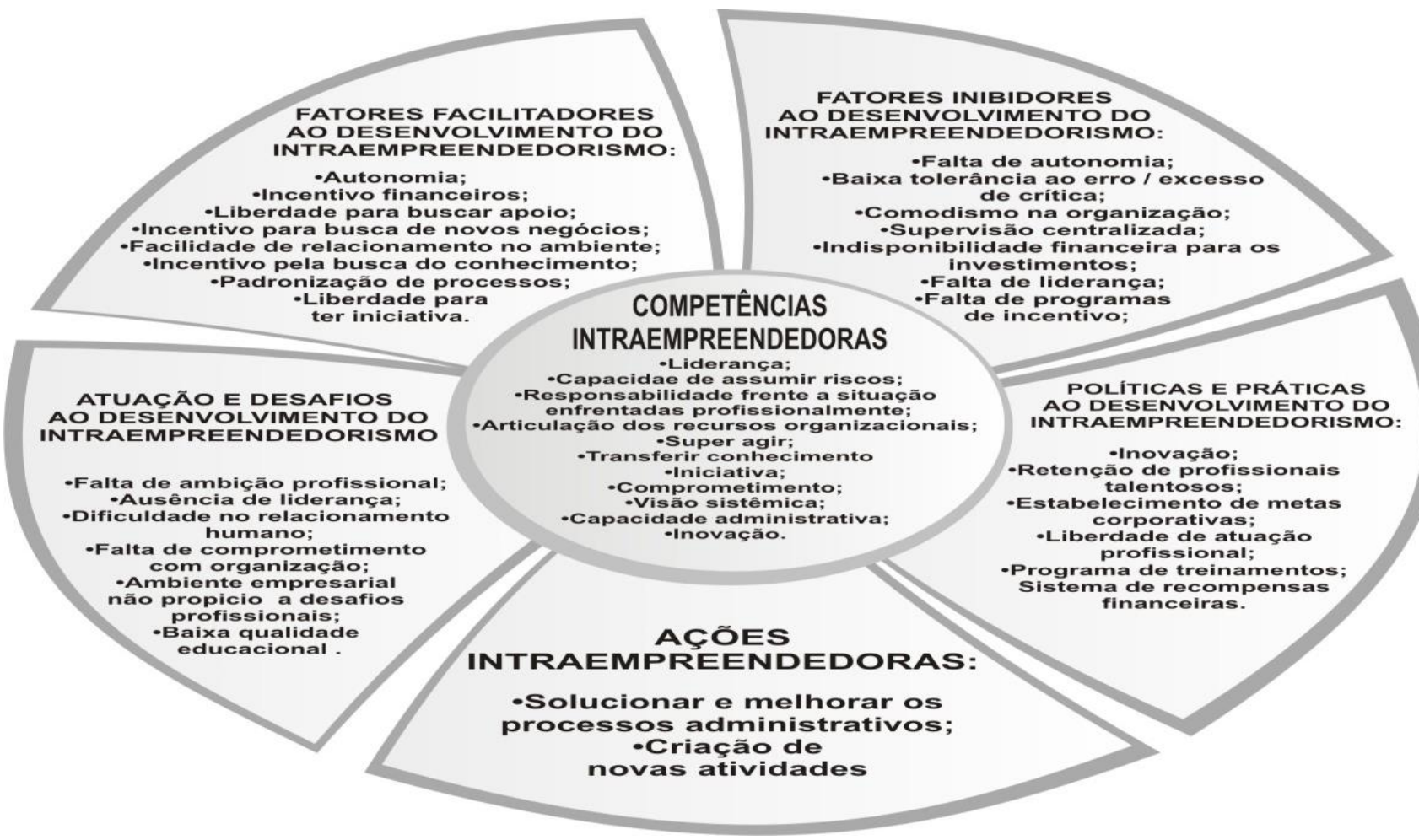

Figura1 - Síntese das Categorias de Respostas

Fonte: Resultado da pesquisa

Os resultados relacionados às competências intraempreendedoras consideram as opiniões dos sócios cotistas empreendedores e dos seis intraempreendedores, que foram manifestadas durante as entrevistas. As competências que emergiram a partir dos depoimentos e que são frutos das vivências pessoais e profissionais dos entrevistados refletem o contexto de trabalho no qual estão inseridos. Sobretudo, ao se considerar que as empresas prestadoras de serviços têm uma estreita relação com suas contratantes, com os clientes destas contratantes, fornecedores, comunidades, agências reguladoras e que todos os intraempreendedores são prepostos legais e respondem oficialmente por estas empresas perante seus contratantes.

O empreendedor T0, considera que são várias as competências para um intraempreendedor:

São várias, vou apenas citar algumas que a meu ver seriam: credibilidade, competência, liderança e capacidade de assumir riscos. [T0]

As competências apontadas pelo empreendedor T0, podem ser entendidas através de Zarifian (2003), que fundamenta seu conceito de competência em três elementos: tomada de 
iniciativa; responsabilidade frente a situações enfrentadas pelo profissional e conhecimento adquirido da inteligência prática, assumindo responsabilidade e dividindo desafios.

Para o empreendedor A0, a capacidade de formar novos profissionais é a principal competência esperada do intraempreendedor, além de ser capaz de encarar desafios e ter uma inquietude profissional na busca de coisas novas.

A capacidade de formar outros gerentes, outros executivos. Ele tem que se sentir seguro, se sentir bom no faz, isso é primordial.

... esta sempre buscando coisas novas, às vezes nem pesando na parte financeira. Ele é profissional, mas não fica só pesando em dinheiro, está aberto a tudo. [A0]

Estas afirmações vêm ao encontro da definição de competência apresenta por Prahalad e Hamel (2005), que definem competência como uma articulação de recursos organizacionais, um aprendizado da organização, um saber-fazer coletivo e complexo, especialmente no que diz respeito à coordenação de diversas habilidades de produção e a integração de múltiplas correntes tecnológicas.

Também encontrou-se nos conceitos de Zarifian (2003) o discurso do empreendedor A0 e pode-se acrescentar os conceitos de Fleury e Fleury (2009) que para os autores competência é um saber-agir responsável e reconhecido, que implica em mobilizar, integrar, transferir conhecimentos e recursos que agreguem valor econômico à organização e social ao indivíduo.

Para os intraempreendedores da empresa Tecdata as competências que os caracterizam são:

Sabe fazer uma análise de tudo, conhecer, pensar. Se você não pensar não chega a uma conclusão. Você pode até não saber de tudo, mas precisa saber que aquilo existe. [T1]

Competência de iniciativa, ter este espírito desafiador, que é uma coisa interessante, se eu não achasse que tinha capacidade nem assumiria algumas funções. [T2]

Ter uma visão sistêmica dos negócios que você esta gerindo, você conhecer de tudo um pouco e às vezes colocar a mão na massa é fundamental. [T3]

As competências de transferência de conhecimentos, o saber-fazer e conhecer de Fleury e Fleury (2009) aparecem na análise do intraempreendedor T1, que se conceitua à luz de Dutra (2004), ao acrescentar que o conceito de competência permite estabelecer o que é esperado da pessoa de forma alinhada ao intento estratégico e às competências organizacionais, por meio da entrega de resultados. 
$\mathrm{T} 2$, destaca a necessidade de ser dedicado, ter capacidade de agir com iniciativa, ser esforçado e estar pronto para encarar novos desafios são competências fundamentais para o intraempreendedor. No discurso T2 foi possível identificar-se as competências de comprometimento de Man e Lau (2005), quando ele destaca que é necessário ser dedicado a empresa.

As competências conceituais de Man e Lau (2005) estão presentes no discurso de T3, quando aponta a necessidade de uma visão sistêmica, uma vez que esta competência consiste na habilidade de observar, analisar e avaliar as situações empresariais de forma subjetivos na busca de caminhos alternativos e na melhor forma de alcançá-los. As competências Organizadoras/Administrativas de Man e Lau (2005) fazem parte do conjunto de T3 ao afirmar que saber delegar aprimora sua capacidade de gestão e controle para desempenhar de forma eficiente suas funções.

Já para os intraempreendedores da empresa Allsan as competências que os caracterizam são:

Ter objetivos, traçar metas e estar sempre determinado e seguir em frente. [A1]

Ter expertise não só de executar, uma das coisas que ele tem que ter também em determinados momentos, ele tem que procurar novas frentes, buscar novos negócios. Tem que chegar e apresentar um projeto. [A2]

São necessárias várias habilidades para os intraempreendedores. Primeiro ele precisa ser comprometido com seu trabalho, buscar sempre a melhor maneira de executar suas tarefas e fazer todas suas atividades profissionais e pessoais da melhor maneira possível. [A3].

As competências de Man e Lau (2005) de relacionamento, organizadoras/administrativas foram identificadas na trajetória profissional de A1, que segundo relato conseguiu diminuir o tempo gasto nas tarefas do dia-a-dia e desta forma pode acompanhar melhor os trabalhos dos demais colaborares interno sob sua liderança através de mecanismos gerenciais mais eficazes. Também foi possível identificar as competências de Comprometimento, que estão ligadas em manter o compromisso com o empreendimento, quando A1 relata a necessidade de traçar metas e sempre estar determinado a seguir em frente.

Para o intraempreendedor A2, são competências intraempreendedora as capacidades de aprendizagem e busca pelo conhecimento, a identificação de oportunidades externa que 
acontecem nos negócios e a utilização do conhecimento no desenvolvimento e busca de novos negócios. O intraempreendedor A2 apontou as competências de Aprendizagem, de Inovação, de Relacionamento e Oportunidades conceituadas por Man e Lau (2005). Para estes autores as competências de inovação estão ligadas à capacidade de replicar o seu portfólio de serviços ao maior número de clientes possíveis.

Aparecem no discurso do intraempreendedor A3 as competências de Inovação, Conceituais e de Equilíbrio Trabalho/Vida pessoal de Man e Lau, que parte do pressuposto que existe uma complementaridade entre a vida pessoal e o trabalho e que ambas não são concorrentes.

O Quadro 1 condensa as competências que surgiram com maior ênfase dos relatos dos intraempreendedores com base nos estudos de Man e Lau (2005), identificando a competência, sua descrição, quem foi o respondente e a ilustração utilizada.

Quadro 1- Identificação de competências segundo Man e Lau (2005)

\begin{tabular}{|c|c|c|c|}
\hline Competência & Descrição & $\begin{array}{l}\text { Responde } \\
\text { nte }\end{array}$ & Ilustração \\
\hline Conceituais & $\begin{array}{l}\text { Habilidade de observar, analisar e } \\
\text { avaliar as situações empresariais de } \\
\text { forma subjetiva }\end{array}$ & $\mathrm{T} 1$ & $\begin{array}{l}\text { Saber fazer uma analise } \\
\text { de tudo, conhecer } e \\
\text { pensar }\end{array}$ \\
\hline Inovação & $\begin{array}{l}\text { Capacidade de replicar o portfólio de } \\
\text { serviços ao maior número de clientes }\end{array}$ & $\mathrm{A} 2$ & $\begin{array}{l}\text { Tem que procurar novas } \\
\text { frentes, buscar novos } \\
\text { negócios }\end{array}$ \\
\hline $\begin{array}{l}\text { Organizadoras/ } \\
\text { administrativas }\end{array}$ & $\begin{array}{l}\text { Gestão de talentos e recursos da } \\
\text { organização }\end{array}$ & $\mathrm{T} 3$ & $\begin{array}{l}\text { Visão sistêmica dos } \\
\text { negócios que você esta } \\
\text { gerindo }\end{array}$ \\
\hline $\begin{array}{l}\text { Comprometime } \\
\text { nto }\end{array}$ & $\begin{array}{l}\text { Manter o compromisso com o } \\
\text { empreendimento mesmo na crise }\end{array}$ & $\mathrm{T} 2$ & $\begin{array}{l}\text { é necessário ser dedicado } \\
\text { a empresa }\end{array}$ \\
\hline
\end{tabular}

Fonte: dados da pesquisa

Os intraempreendedores entrevistados ressaltam como competências para estes cenários em que estão inseridos a capacidade de saber-fazer, conhecimento, iniciativa, espírito desafiador, visão sistêmica dos negócios, ser sempre determinado e estar comprometido com 
as funções e atividades que desempenham. Estes pressupostos podem ser entendidos à luz de Jing (2007), que o intraempreendedor é a pessoa que defende as práticas do empreendedorismo nas empresas existentes e que suas competências podem determinar o resultado geral da organização e até seu crescimento.

As competências destacadas pelos intraempreendedoras e empreendedores corroboram muito no entendimento da natureza dos serviços que estão inseridos e das exigências feitas pelas contratantes destes serviços às empresas prestadoras de serviços. As ações intraempreendedoras foram apontadas pelos participantes como atividades para solucionar e melhorar os processos administrativos, criação de novas atividades e outras ações relevantes para as organizações. Ao que tudo indica estes exemplos de ações intraempreendedora narradas pelos respondentes da pesquisa integram com clareza as suas competências, ora pessoais, em outros momentos técnicas ou de relacionamentos. Os fragmentos apontados trazem no seu bojo aspectos contributivos não só do ponto de vista operacional, mas, sobretudo quando estes intraempreendedores apresentam soluções benéficas, práticas e de sucesso para as empresas como resultado das suas ações. Pinchot e Pellman (2004) corroboram com os resultados acima ao afirmarem que o intraempreendedor é aquele que transforma uma idéia em realidade dentro de uma empresa. $\mathrm{E}$ é complementado pela pesquisa de Ping et al. (2010) mostrando que as ações intraempreendedoras são uma forma eficaz de promover o crescimento sustentável das organizações. Sintetizando as respostas dos sócios cotistas empreendedores e dos intraempreendedores das duas empresas pesquisadas, o Quadro 2 aponta expressões chaves identificado nas respostas dadas sobre os fatores que podem facilitar ou inibir o desenvolvimento do intraempreendedorismo no ambiente organizacional.

Quadro 2 - Expressões chaves do que pode inibir ou facilitar

\begin{tabular}{|l|l|}
\hline O que pode facilitar & O que pode inibir \\
\hline Autonomia. & Falta de autonomia. \\
\hline Incentivos financeiros. & Baixa tolerância ao erro/ excesso de crítica. \\
\hline Liberdade para buscar apoio & Comodismo na organização \\
\hline Incentivo para busca de novos negócios & Supervisão centralizadora \\
\hline Facilidade de relacionamento no ambiente & $\begin{array}{l}\text { Indisponibilidade financeira para os } \\
\text { investimentos }\end{array}$ \\
\hline
\end{tabular}




\begin{tabular}{|l|l|}
\hline O que pode facilitar & O que pode inibir \\
\hline Facilidade de relacionamento no ambiente & $\begin{array}{l}\text { Indisponibilidade financeira para os } \\
\text { investimentos }\end{array}$ \\
\hline Incentivo pela busca do conhecimento & Falta de liderança \\
\hline Padronização de processos & Falta de programas de incentivos \\
\hline Liberdade para ter iniciativa & \\
\hline
\end{tabular}

Fonte: Resultado da pesquisa

No Quadro 2, observa-se que características como autonomia, liberdade de buscar apoio e de ter iniciativa, incentivos financeiros e de busca de novos negócios são fatores facilitadores ao intraempreendedorismo. Por outro lado, os fatores inibidores se expressão frente à falta de autonomia, baixa tolerância ao erro ou excesso de crítica, supervisão centralizadora, falta de liderança e de programas de incentivos. Essas evidências apontam que estes fatores estão muito centrados na liderança empreendedora das organizações pesquisadas. Bessant e Tidd (2009) e Baron e Shane (2007) abordam a importância dos colaboradores internos no processo de empreendedor, mas enfatizam o papel relevante da liderança empreendedora, seja para dar continuidade no processo de inovação ou para gerar eficácia nos trabalhos organizacionais.

Para aplicação desses resultados no contexto de empresas, sobretudo de pequeno porte, sugere-se atenção a possíveis entraves que a liderança empreendedora possa causar no ambiente e como conseqüência, gerar fatores que inibam ações intraempreendedoras.

Não obstante, os empreendedores entendem que as atuações e desafios do intraempreendedorismo estão no perfil dos profissionais e na sua qualificação. Já para os intraempreendedores estas ações e desafios devem partir da empresa, que deverá propiciar desafios para estimular estas ações por parte do seu quadro de funcionários.

Este tipo de conflito pode ser entendido através de Hashimoto (2009), quando diz que foram Covin e Miles (1999) que melhor demonstraram as diferenças entre empreendedorismo corporativo e intraempreendedorismo, ao estabelecerem três divisões de classificação do empreendedorismo corporativo. A primeira se refere a uma organização já existente que promove o lançamento de novos negócios alinhado com a concepção do empreendedorismo corporativo, que segundo Antoncic e Hisrich (2001) é o empreendedorismo dentro da empresa já existente, tratando-se de um processo de identificação e desenvolvimento de oportunidade independente dos recursos disponíveis. A segunda divisão é tocante ao indivíduo que tem novas idéias para produtos e serviços no ambiente organizacional sendo caracterizado como 
intraempreendedor, esta ação ocorre mesmo quando a organização não oferece um clima favorável ou apropriado à geração de novos produtos, serviços, processos, ou seja, o funcionário é capaz de gerar um processo de inovação corporativo. A terceira classificação ocorre quando uma organização tem uma filosofia empreendedora, existe um empreendedorismo corporativo formal. Neste caso a organização busca facilitar de todas as formas o surgimento de oportunidades empreendedoras e seus colaboradores também podem ser chamados de intraempreendedor.

Sob a percepção dos respondentes, a consolidação de uma política e prática eficaz para o desenvolvimento do intraempreendedorismo, faz-se necessário o incentivo à inovação, a retenção de talento, o estabelecimento de metas, a liberdade de atuação profissional, a descentralização das informações, implementação de programas de treinamentos e a criação de um sistema de recompensas financeiras pelas empresas.

Estes resultados propiciaram uma melhor compreensão sobre as competências que caracterizam os intraempreendedores, além de abrir caminhos para o despertar de uma cultura empreendedora, que sustente as ações que podem diferenciar uma empresa da outra. Outra perspectiva é a de que por meio do entendimento destes resultados, há possibilidade para melhoria do desempenho operacional das empresas prestadoras de serviços e assim, permitir reflexões dos principais fatores que podem inibir ou facilitar ações intraempreendedoras no quadro de colaboradores. 


\section{Considerações Finais}

Esta pesquisa buscou analisar quais são as competências que caracterizam o intraempreendedor sob sua ótica e dos empreendedores das empresas prestadoras de serviços que atuam junto a Concessionárias de Serviços Públicos de Águas e Esgotos e tem seus contratos de prestação de serviços gerenciados de forma autônoma um dos outros o que as classificam como Unidade de Negócios. Estas gestões contratuais das empresas contam com profissionais que são designados como prepostos junto aos clientes podendo tomar todas as decisões necessárias para execução dos serviços, respondendo oficialmente por todas as ações que são executadas durante a vigência contratual.

Os resultados obtidos na pesquisa de duas das categorias analisadas, conceito de empreendedor e intraempreendedor, corroboram para o entendimento do que vem a ser estes atores no contexto das empresas pesquisadas. As evidências desses resultados apontam para a importância da autonomia, incentivo pela busca do conhecimento, facilidade de relacionamento no ambiente e liberdade para buscar apoio visando abertura para iniciativa frente aos desafios, como aspectos colaboradores para o desenvolvimento das competências intraempreendedoras. Contrário a isto, fatores tais como, a baixa tolerância ao erro acompanhado de crítica, supervisão centralizadora, ausência de programas de incentivos, dentre outros, descaracterizam por completo uma empresa empreendedora que conta com intraempreendedores. Essas últimas características fortalecem uma gestão tradicional, com colaboradores dependentes, acomodados e desmotivados. Por conseqüência, esse cenário desfavorece os pressupostos idealizados pelo desenvolvimento do intraempreendedorismo, dificultando tanto a liderança empreendedora quanto as manifestações intraempreendedoras de seus colaboradores e assim, o desenvolvimento de competências intraempreendedoras.

Refletindo os resultados da pesquisa, ficou evidente que, ao dialogar com os empreendedores acerca das competências empreendedoras, as percepções desses respondentes convergem com o que Prahalad e Hamel (2005) pontuam no sentido de se articular os recursos organizacionais para o desenvolvimento produtivo da empresa. Corrobora com isso, Zarifian (2003) que fundamenta seu conceito de competência em três elementos: tomada de iniciativa; responsabilidade frente a situações enfrentadas pelo profissional e conhecimento adquirido da inteligência prática, assumindo responsabilidade e dividindo desafios.

Por outro lado, no dialogo com os intraempreendedores, pode-se evidenciar que as competências mais citadas foram às competências conceituais, de inovação, 
organizadoras/administrativas e de comprometimento, embora as outras seis também se fizessem presentes, mas não foram tão expressivas, quando analisadas à luz da pesquisa de Man e Lau (2005). Disso, deduz-se que pela natureza da atividade desenvolvida pelos intraempreendedores no papel de prepostos das empresas contratantes, as demandas encaminham para ações já delineadas em função de contratos, visando o cumprimento das exigências contratuais. Esses aspectos potencializam o desenvolvimento das quatro competências acima citadas, mas não excluem as demais.

Este modelo de negócios abre novas perspectivas para futuros estudos e entendimento das especificidades de entender as competências dos intraempreendedores neste ambiente.

Essa pesquisa não é um fim em si mesmo. Mas, apresenta resultados que contribuem para a compreensão das competências que caracterizam o intraempreendedor em empresas prestadoras de serviços. Entretanto, para que o aprofundamento teórico acerca dessa temática ganhe mais robustez e densidade, outras pesquisas precisam ser desenvolvidas. Assim, esse estudo de caráter qualitativo e exploratório não propicia alcance para que se generalizem seus resultados para outros ramos de trabalho. Além disso, não adotou como critério porte da empresa e sim, o fato de serem prestadoras de serviços no setor de saneamento básico.

Dessa forma, considerando a maturidade adquirida com o desenvolvimento dessa pesquisa, sugerem-se alternativas para futuros trabalhos. Acredita-se que resultados se consolidem com o desenvolvimento de pesquisas sob essa perspectiva em organizações prestadoras de serviços de outros segmentos, possibilitando a verificação de recorrência dos resultados aqui encontrados. Outra percepção de ganhos para a área de conhecimento seria a realização de pesquisas com o objetivo de identificar os fatores da liderança empreendedora frente às práticas favorecedoras do comportamento intraempreendedor e resultados alcançados com estas medidas. E por fim, a busca de novos conhecimentos por meio da investigação das competências intraempreendedoras em empresas de pequeno e médio porte. 


\section{Referências}

ANTONCIC, H.; HISRICH, R.D. Clarifying the intrapreneurship concept. Journal of Small Business and Enterprise Development: v.10, n 1, ABI/INFORM Global, 2003.

BARON, R. A.; SHANE, S.A. Empreendedorismo: uma visão do processo. São Paulo: Thomson Learning, 2007.

BESSANT, J.; TIDD, J. Inovação e empreendedorismo. Porto Alegre: Bookman, 2009.

BOOTH, W. C.; COLOMB, G. G.; WILliAMS, J. M. A arte da pesquisa. 2. ed São Paulo: Martins Fontes, 2005

COVIN, J. G. \& MILES, M. P. Corporate Entrepreneurship and the Pursuit of Competitive Advantage. Entrepreneurship Theory \& Practice, p.47-63, Spring 1999.

CUNNIGHAN, J.; LISCHERON, J. Defining entrepreneuship. Journal of Small Business Management, V. 29, no 1., jan. 1991.

DUTRA, J.S. Competências. São Paulo: Atlas, 2004.

FALCONE, T.; OSBORNE S. Entrepreneurship : a diverse concept in a diverse world. Anais: IberoAcademy. Academy of Management. Faculdade de Economia - Universidade Nova de Lisboa. Lisbon, Portugal - December, 8-11,2005.

FILION, L. J. Diferenças entre sistemas gerenciais de empreendedores e operadores de pequenos negócios. RAE - Revista de Administração de Empresas, São Paulo, v.39, n.4, pág. 6- 20,out/dez 1999.

FLEURY, M.T.L: FLEURY, A. Construindo o Conceito de Competência.. RAE - Revista de Administração de Empresas, São Paulo, p. 183 - 196, 2001.

GARCIA, U. L.; GIMENEZ, F.A.P.; TOLEDO, A. Ações e comportamento intraempreendedores: uma escala de mensuração. São Paulo: Anais do V EGEPE, 2008. 
GODOI, C. K.; MELO, R.B.; SILVA, A.B. Pesquisa qualitativa em estudos organizacionais: paradigmas, estratégias e métodos. São Paulo: Saraiva, 2006.

GODOY, A.S., Refletindo sobre critérios de qualidade das pesquisas qualitativas. Revista Eletrônica de Gestão Organizacional. São Paulo, v.3, n.2, mai/ago, 2005.

HASHIMOTO, M. Espírito empreendedor nas organizações: aumentando a competitividade através do intra-empreendedorismo. São Paulo: Saraiva 2006.

HASHIMOTO, M. Organizações intra-empreendedoras: construindo a ponte entre clima interno e desempenho superior, 2009. Tese (doutorado) - Escola de Administração de Empresas de São Paulo, FGV, 2009.

HISRICH, R. D.; PETERS, M.P.; SHEPHERD, D.A. Empreendedorismo. 3 ed. Porto Alegre: Bookman, 2009.

JUDICE, V.; COZZI, A.; MENDES, L.A.L. Empreendedorismo Corporativo: Revisão teórica e aplicações na Fundação Don Cabral. Paulo: Anais do V EGEPE, 2008.

LE BOTERF, G. Desenvolvendo a competência dos profissionais. 3 ed. Porto Alegre: Armed, 2003

LI, J. A study on the mechanism of intrapreneur`s Growth. Technology Economics, p. 9 $11,2007$.

MAN, T. W. Y.; LAU, T. The context of entrepreneurship in Hong Kong, An investigation through the patterns of entrepreneurial competencies in contrasting industrial environments. Journal of Small Bussiness and Entreprise Development, v. 12, n.4, 2005.

McCLELLAND, D. Characteristics of Successful Entrepreneurs, The Journal of Creative Behavior, v.21, n.3, p.219-233, 1987. 
MELLO, S.C.B.; LEÂO, A.L.M.S.; PAIVA, F.G. Competências empreendedoras de dirigentes de empresas brasileiras de médio e grande porte que atuam em serviços da nova economia. Revista de Administração Contemporânea, Curitiba: vol.10, nº4, 2006.

MITCHELMORE, S.: ROWLEY, J. Entrepreneurial competencies: a literature review and development agenda. International Journal of Entrepreneurial Behaviour \& Research, Machester: vol.16, n², 2010.

NASSIF, V.M.J.; AMARAL, D.J.; CERRETTO, C. SOARES, M.T.R. Understanding the brazilian entrepreneur through social representation. Easter Academy of Management. Hatford, CT- USA, 2009

OLIVEIRA, J.B.; FILION, L.J.; CHIRITA, M.G. Estudo das linhas de pesquisa sobre os intraempreendedores e organizações empreendedoras: exame da documentação de 1996 2006. São Paulo: Anais do V EGEPE, 2008.

PINCHOT, G. III.; PELLMAN, R. Intra-empreendedorismo na prática: um guia de inovação nos negócios. Rio de Janeiro: Elsevier, 2004.

PING, W. L.; LIE, J.; NAIQIU, L.; ZHENGZHONG, X. A review and prospect of research on human resource management of intrampreneurship. Advanced Management Science (ICAMS), IEEE International Conference. Chengdu, China. p.456- 460, 2010.

PIOVESAN, A.; TEMPORINI, E.R. Pesquisa exploratória: procedimento metodológico para o estudo de fatores humanos no campo da saúde pública. Revista Saúde Pública, v.29, 1995.

PRAHALAD, C.K., HAMEL, G. The Core Competence of the corporation. Harvard Business Review, v.68, n.3, May-June 1990.

RICHARDSON, R.J. Pesquisa Social: métodos e técnicas. 3.ed. São Paulo Atlas: 1999.

SCHUMPETER, J.A. Teoria do Desenvolvimento Econômico. São Paulo: Abril Cultural, 1983 [1934] 
SHAPERO, A. Some social dimension of entrepreneurship. Artigo apresentado no Congresso sobre Entrepreneurship Research. Documento Resumo, 28 p. ED 36.351. Waco, TX, 24-25 de Mar.1980.

SIMON, H. A. Administrative Behavior: study of decision-making processes in administrative organization. New York: Macmillan, 2002.

STEVENSON. H.H. et JARILLO, J. C. A Paradigm of Entrepreneurship: Entrepreneurial Management, Strategic Management Journal, 11 (Special issue), 1990.

TEODORO, P.; OLIVEIRA, V. C. S. O empreendedorismo por necessidade e a precariedade da formação gerencial do pequeno empreendedor brasileiro. In: ÉSTHER, Â. B.; PAÇOCUNHA, E.; SANÁBIO, M. T. (orgs). Pequenas empresas: reflexões e perspectivas de ação. Minas Gerais: editora UFJF, 2006. 348 p.

TIMMONS, J.A. New venture creation. Boston: Irwin McGraw-Hill, 4. ed., 1994.

VIEIRA, A. M: et al. Gestão e desenvolvimento de competências gerenciais relacionadas à tecnologia da informação. Tribunal de Contas da União (TCU), Brasília, 2003.

ZARIFIAN, P. O Modelo competências: trajetórias históricas, desafios atuais e propostas. São Paulo: SENAC, 2003. 